can be used in solving problems of dispersal of smoke and other forms of atmospheric pollution, and in providing complete, if complex, expressions for evaporation-rates from open water. These expressions would have much greater practical value if they were accompanied by short tables giving a range of values of the stability-dependent constants that appear in equations $8 \cdot 55,8 \cdot 56$ and elsewhere: not everyone who will want to use this chapter will possess tables of incomplete gamma functions or know where to find them.

For a summary impression of the book as a whole we can go back to its beginning. It is dedicated to Sir David Brunt: it is a worthy offering.

H. L. Penman

\section{SELECTIONS FROM THE WORKS OF C. G. JUNG}

\section{Psychological Reflections}

An Anthology of the Writings of C. G. Jung. Selected and edited by Jolande Jacobi. Pp. xxvii +342. (London: Routledge and Kegan Paul, Ltd., 1953.) 30s. net.

THIS anthology of Jung's writings, compiled by Dr. J. Jacobi, is a bedside book: "The object is to show by means of a cross-section a few of the more important aspects of existence reflected in humanity in general, when understood and illumin. ated by Jung's Psychology. It was not the intention to present Jung's theory ; therefore everything which is technical has been excluded".

The publishers recommend this book "not only for the use of scientists, but for all who want to arrive at a better knowledge of themselves and the world". They are presupposing that there is a discovery to be made which is not only scientific discovery-discovery by observation and deduction therefrom in strict accordance with logical rules-but also a discovery by reflexion, a moral discovery.

The whcle work of Jung as a man of science poses the question of validation. If the basis of science turns out to be 'unscientific' and 'facts' are as indeterminate as any symbolic experience, then we have to admit that Prof. C. A. Coulson is right when he states that facts say nothing at all ; what matters about truth is not the facts, but the interpretation of the facts.

Just as, in physical science, concepts like atoms and electrons are logically unobservable but are validated by analogy, so it is with the working of the mind. What are being experienced there are not fixed things but reflexions of experiences which manifest themselves in symbolical terms. Man to-day, however, is conditioned by his 'scientific' training to think quantitatively and forgets that validation is experienced also in image thinking. Verbal thinking and image thinking go side by side, and Prof. H. H. Price says in his book, "Thinking and Experience" (p. 252): "If rainbows, reflections, mirages and the like had been less common than they are, philosophers would have denied their existence on a priori grounds. For how can there be entities which are at once physical and non-physical, in the physical world and yet not of it, existing from some points of view and not from others, spatial but lacking backs or insides ? The fate of mental images, in these latter Verbalistic days, has been somewhat similar. We have the misfortune to live in the most word-ridden civilization in history where thousands and tens of thousands spend their entire working lives in nothing but the manipulation of words. The whole of our higher education is directed to the encouragement of verbal thinking. Let us hope that our successors will be wiser, and will encourage both".

It is with image thinking that Jung's work is concerned. Those who are not too much bogged down in verbal logic, and thus able to experience that there is active also a process of imaging in man's faculties of cognition, will be able to appreciate the significance of this book. The anthology is a useful introduction to the rest of Jung's work. It shows clearly the fundamental weakness of Jung's psychology, which by having no fixed scheme appears to be full of contradictions and paradoxes; but this weakness is at the same time a sign of its greatness. For, life in the psyche manifests itself thus: "You cannot. step twice into the same river, because fresh waters are ever flowing in upon you". H. WESTMANN

\section{THE PROGRESS OF PLANT PHYSIOLOGY}

\section{Annual Review of Plant Physiology}

Vol. 4. Daniel I. Arnon (Editor). Leonard Machlis (Associate Editor). Pp. $x+453$. (Stanford, Calif. : Annual Reviews Inc., 1953.) 6 dollars.

JOTHING could emphasize more strikingly the rapidity of the growth in knowledge of the physiology of plants than the "Annual Reviews of Plant Physiology" published under the general editorship of Dr. D. I. Arnon and Dr. L. Machlis. No longer can the plant physiologist, by the reading of original papers only, hope to keep up to date with all the aspects of his subject, and all students and teachers of plant physiology should feel grateful to the editors, contributors and publishers of these reviews for making it possible for the generality of plant physiologists to obtain a reasonable appreciation of the work done in those branches of the subject outside their own specialist interests. Each annual volume, four of which have appeared at the time of writing, does not attempt to cover the whole field of plant physiology, but contains a number of reviews, fifteen in each of Volumes 3 and 4, written by authorities in their respective fields, of a limited number of particular aspects of the science, those which are undergoing rapid development being dealt with more frequently than those which are attracting less attention as current subjects of research. Thus, photosynthesis was dealt with in 1952 by E. Rabinowitch, while in the 1953 volume it is reviewed by A. H. Brown and A. W. Frenkel and reviews on certain. aspects of photosynthesis by D. Burk and L. R. Blinks are promised for 1954. On the other hand, a number of topics such as the physiology of root growth, the biogenesis of terpenes, the plant sterols. and fluorescent substances in plants by H. Burström, A. J. Haagen-Smit, W. Bergmann and R. H. Goodwin respectively are reviewed in the 1953 volume but are not in the list of subjects for 1952 or 1954. This policy would appear to be a wise one, for it has the result that each branch of the subject considered contains enough material for an article of reasonable length the writing and reading of which are worth while. 